\title{
Patients' Awareness and Perception of Rights at Educational and Non- Educational Hospitals In Zagazig City
}

\author{
${ }^{1}$ Nahla Ashraf Zaitoun, ${ }^{2}$ Dina Ali Shokry, ${ }^{3}$ Maha Abdelrahman Mowafy \\ ${ }^{1}$ Family Medicine Department, Faculty of Medicine, Zagazig University, Egypt. ${ }^{2}$ Forensic \\ Medicine and Toxicology Department, ${ }^{3}$ Family Medicine Department, Faculty of Medicine, \\ Cairo University, Egypt.
}

\begin{abstract}
Background: Patient's rights, is an important part of modern healthcare practice and considered a reflection of human rights in the modern-day society. Promoting patient's rights is a priority of healthcare policy makers and health care providers in clinical practice especially in Low- and Middle-Income Countries where healthcare ethics is neglected. Objective: The current study was conducted to assess patients' awareness about their rights in educational and non-educational hospitals. Method: An observational cross-sectional study was carried out over a period of six months; from March to September 2017, at Internal medicine and Surgical departments. A sample size of 360 patients were randomly selected (240 from Zagazig University hospitals/educational hospital and 120 from General Zagazig hospital \& Ahrar hospital/non-educational) selected randomly and respectively. Data was collected using an interview-based questionnaire. Results: There was significant difference in perception of rights between patients in educational and non-educational hospitals, moreover, between surgical and internal medicine departments mainly in the non-educational hospitals. The most practiced rights from the patients' perspective were asking for permission prior to examination, exposure of any part of the body and confidentiality of the admission file. Conclusion: The difference between hospitals in the implementation of ehtics and patient rights is highly linked to the attitude of the doctors in treating the patient and being trained to respect privacy and confidentiality of patients. Educational hospitals are more practing patients' rights than noneducational ones.
\end{abstract}

Key words: Medical ethics / Rights /confidentiality

Corresponding author: Nahla Ashraf Zaitoun Email :nahla_zaitoun@hotmail.com

\section{Introduction}

Patient's rights, recently has become an important part of modern healthcare practice which considered as aterm in health sciences practice and a reflection of human rights in the modern day society. ${ }^{1}$ Historically, Hippocrate was the first one who declared for protecting patients' rights, imposing on physicians the importance of respecting patients' autonomy. In 1948, United Nations published the Universal Declaration of
Human Rights Act which passed legislations on patients' rights ${ }^{2}$ and these rights has been developed based on the concept of the equality of all human being $^{3}$, which considered as a reflection of human rights in modern day. ${ }^{4}$ Health care patients have rights, which must be acknowledged and protected which include observance of acceptable physical, mental, spiritual and social needs and health care 
providers are responsible for establishing

and maintaining patients' rights. ${ }^{5}$

Table (1): Patients' awareness about their rights

\begin{tabular}{|c|c|c|c|c|c|}
\hline & \multicolumn{2}{|c|}{ Educational } & \multicolumn{2}{|c|}{$\begin{array}{c}\text { Non- } \\
\text { educational }\end{array}$} & \multirow[t]{2}{*}{ P-value } \\
\hline & No & $\%$ & No & $\%$ & \\
\hline $\begin{array}{l}\text { The right to have enough time to ask about your } \\
\text { disease and treatment? }\end{array}$ & 127 & 55.2 & 47 & 39.16 & 0.16 \\
\hline $\begin{array}{l}\text { The right to have privacy when you are discussing } \\
\text { benefit, risks, duration of treatment with your } \\
\text { physician? }\end{array}$ & 132 & 55 & 97 & 80.83 & $<0.001 *$ \\
\hline The right to have privacy during examination & 84 & 48.83 & 20 & 17.54 & $<0.001^{*}$ \\
\hline $\begin{array}{l}\text { The right to had detailed information about the } \\
\text { nature of your illness and diagnosis? }\end{array}$ & 157 & 68.25 & 54 & 45 & \\
\hline $\begin{array}{l}\text { The right to have detailed Information about } \\
\text { benefit, risks, duration of suggested treatment and } \\
\text { its alternatives? }\end{array}$ & 157 & 68.25 & 54 & 45 & $<0.001 *$ \\
\hline $\begin{array}{l}\text { The right to refuse any treatment or } \\
\text { procedure related to your illness? }\end{array}$ & 17 & 7.08 & 17 & 14.16 & $0.001 *$ \\
\hline
\end{tabular}

$* P$-value $<0.05$ considered to be significant

Informed consent has become the first paradigm for protecting and saving the legal rights of patients and it is important in guiding the ethical practice of medicine. It may be used for different purposes in different contexts: legal, ethical or administrative. Although these causes overlap, they are not identical, thus leading to different standards and criteria for what constitutes "adequate" informed consent. ${ }^{6}$ During the past few years, Egypt has implemented several diverse legal, political and administrative mechanisms to deal with health care ethical problems. Despite major achievements, several problems persist, including unethical behavior of health care workers, inequity, and poor patient realization of selfempowerment. $^{7}$

Healthcare ethics is neglected in clinical practice in LMICs (Low- and MiddleIncome Countries) such as Egypt. To our knowledge, there have been no previous surveys of assessment of perception of the patients about their rights. The objective of this study was to assess patient awareness and perception about his right as regards to their doctor's practice and to which extent does the patient obtained his rights in a tertiary educational hospital and noneducational hospitals in Zagazig City, Egypt.

\section{Method}

This is an observational cross-sectional study aimed to assess patients' awareness about their rights in Zagazig University hospitals, Zagazig General and Ahrar hospital these hospitals provide teritary level of of patient care covering major medical and surgical disciplines. Zagazig University hospitals represented the educational hospitals and Zagazig-General and Ahrar hospital represented the noneducational hospitals. The study was carried out over a period of six months; from March to September 2017, at the following departments:Internal medicine from medical department and general surgery, Obstetrics and Gynecology, Ophthalmology and Otorhinolaryngology from surgical departments. A convenience sample size of 360 in the studied hospitals was included in the study. This was 
disptributed proportioannly between hospitals based on the attendence rate of the patients in all studied hospitals takeing

Table (2): Patient perception about doctor's practice of confidentiality and privacy:

\begin{tabular}{|c|c|c|c|c|c|}
\hline & \multicolumn{2}{|c|}{ Educational } & \multicolumn{2}{|c|}{ Non-educational } & \multirow{2}{*}{ P-value } \\
\hline & No & $\%$ & No & $\%$ & \\
\hline Permission before starting clinical examination & 215 & 89.5 & 94 & 78.3 & $<0.001 *$ \\
\hline $\begin{array}{l}\text { Permission before expose any part of the body } \\
\text { for examination }\end{array}$ & 220 & 91.6 & 73 & 60.8 & $<0.001 *$ \\
\hline Confidentiality of admission file & 142 & 61.7 & 53 & 44.16 & $<0.001 *$ \\
\hline Receiving information about diagnosis & 99 & 43.04 & 34 & 28.3 & $<0.001 *$ \\
\hline $\begin{array}{l}\text { Respecting privacy during discussing diagnosis } \\
\text { and treatment }\end{array}$ & 132 & 55 & 17 & 14.16 & $<0.001 *$ \\
\hline
\end{tabular}

$* P$-value $<0.05$ considered to be significant

Patients who were admitted as in-patients and had remained at least three days not more than 7 days in the hospital to enable them to exercise their rights ${ }^{8}$ were invited to participate, while serious psychiatirc disorder and in intensive care unit, and less than 18 years old were excluded from the study.

Data was collected from study participants using an interview-based questionnaire, after explaining the purpose and aim of the study to those who participate and obtaining consent for the questionnaire to be filled anonymously and responses of all study participants were treated confidentially. A pilot study was carried out to evaluate the validity and reliability of the interviewed-based questionnaire applied on patients. Test-retest reliability was assessed using the questionnaire two times on $10 \%$ of the sample size (36 patients). Based on the result of pilot study some modifications and rearrangement of some questions were done. The questionnaires were translated using a back-translation technique. An expert translated the original questionnaire from Arabic into English. The Arabic version of the questionnaires was translated back into English by a bilingual individual. The back-translated and original versions of the questionnaire was compared with attention given to the meaning and grammar. in consideration the patients admitted for surgical operation in surgical departments.
Cronbach's Alpha test was used to measure consistency of the questionnaire a reliability of coefficient of 0.708 was considered to be accepted.

An interview-based questionnaire had been held to assess the practice of healthcare ethics and awareness about the patient's rights. It is divided into three parts: The first part of the questionnaire is concerned with socio-demographic characteristics such as (age, gender, residence, education level and income). The second part is concerned with inquiries about patient's bill of right. It includes 10 questions about patient's rights. Each question is answered by yes or no or not sure. Patients are asked whether they are aware of their rights. The third part is concerned with the patient awareness about the informed consent and application of informed consent in the studied hospitals, it includes close ended questions, each question is answered by yes or no or not sure and one question about who ask for informed consent.

Questions were developed from review of qualitative and quantitative literature for relevant Younis, et al, ${ }^{9}$ and Bazmi, et al ${ }^{10}$ including guidelines on principles of patients' rights provided by the World Medical Association 2015.

Patients were selected by systematic random technique (every third patient attending the hospital for invasive 
procedure were taken). Selection of departments had been done according to the frequency of operations for proper assessment.

Table (3): Patients' perception about their rights regarding signing, reading and understanding the informed consent:

\begin{tabular}{|c|c|c|c|c|c|}
\hline & \multicolumn{2}{|c|}{ Educational } & \multicolumn{2}{|c|}{ Non-educational } & \multirow{2}{*}{ P-value } \\
\hline & No & $\%$ & No & $\%$ & \\
\hline Signed the informed consent & 176 & 76.52 & 97 & 80.83 & 0.11 \\
\hline $\begin{array}{l}\text { Thinking before signing the informed } \\
\text { consent }\end{array}$ & 45 & 25.56 & 47 & 48.45 & $<0.001 *$ \\
\hline $\begin{array}{l}\text { Physician who asked to sign the consent } \\
\text { form }\end{array}$ & 23 & 13.06 & 22 & 22.68 & $0.017 *$ \\
\hline Reading the consent form & 40 & 22.72 & 50 & 51.54 & $<0.001 *$ \\
\hline Understanding consent form & 59 & 33.52 & 10 & 10.30 & $<0.001^{*}$ \\
\hline
\end{tabular}

General surgery, Ophthalmology, Obstetrics and Gynecology, Otorhinolaryngology and the internal medicine department were the only one with sufficient frequency of operations in all non-educational hospitals.

Obstetrics and Gynecology was selected because it is a separate department in both educational and non-educational hospitals that served many patients and had a lot of operations, while the special departments were excluded due to limited number of operations that carried out in noneducational hospitals.

Ophthalmology and Otorhinolaryngology were treated as one department due to limited number of physicians in noneducational hospitals and limited operation done in those hospitals compared with educational hospital.

\section{Data management}

The Collected data were recorded then presented and analyzed using SPSS (Statistical Package for the Social Sciences) version 22.0 and Epi info for windows version 3.5, data were represented in tables as frequencies and percentages. Quantitative variables were expressed as the mean \pm standard deviation (SD) while the qualitative variables were expressed as a number and percentage. Chi square test was used to detect the relation between different qualitative variables.
The results were considered statistically significant when the significant probability ( $\mathrm{P}$ value $<0.05 *)$.

Ethical consideration and administrative approach: Ethical approval for the study was obtained from studied hospitals, ethical review committee and all study participants' fulfilled consent for the study according to Helsinki declarations of biomedical ethics.

\section{Results}

This study was carried out by using interviewed-based questionnaire which divided into three parts (demographic part, awareness about patients' bill of rights and awareness about the informed consent).

The patients included 128 male and 232 females with mean age $44.825 \pm 16.25$ in educational hospitals and $37.03 \pm 13.45$ in non-educational hospitals and about 229 patients from urban area. About $36.25 \%$ of patients were illiterate compared to $15.83 \%$ in non-educational and about half of the patients in both hospitals were reading and writing. Patients' awareness and their opinion about receiving suitable care in different items of the rights charter are shown in Table 1, the least were found in had the right to refuse the treatment $7.08 \%$ \& $14.16 \%$ and in the right to have privacy during examination. 
The most practiced rights from the patients' perspective were asking for permission prior to examination, exposure of any part of the body and confidentiality of the

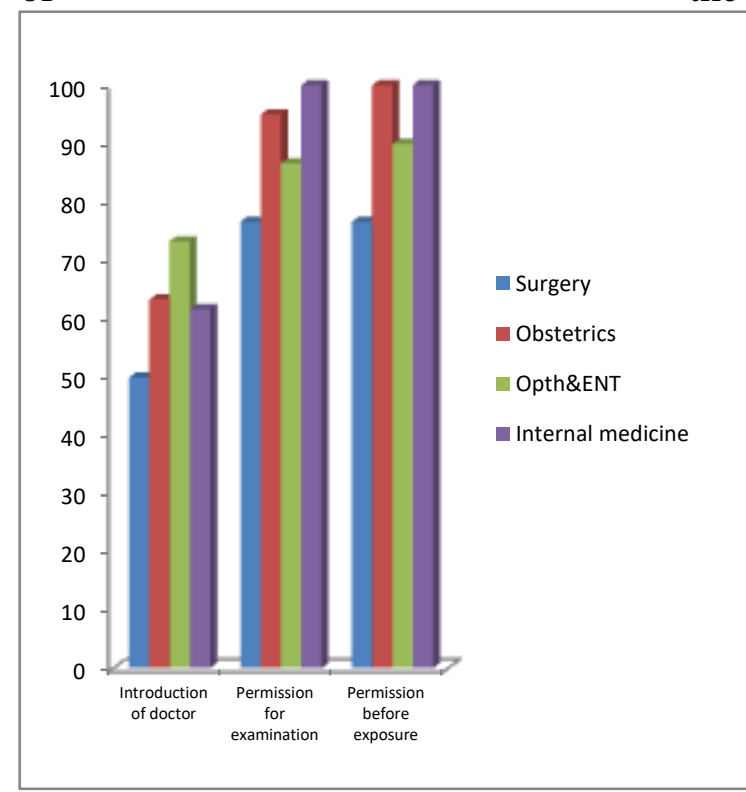

Figure (1): Introduction, permission for clinical examination and permission by different specialties in educational hospitals.

admission file $89.5 \%, 91.6 \%$ and $61.7 \%$ in educational hospitals compared to $78.3 \%$, $60.8 \%$ and $44.16 \%$ in non-educational hospitals respectively. About $28.33 \%$ of patients in non-educational hospitals received information but limited about their diagnosis and $41.67 \%$ not understand the information due to using of medical terms in explaining the benefits, risks and duration of suggested treatment and $98.11 \%$ received information from the attending physician. However, in educational hospitals $43.04 \%$ of patients received information about the nature of disease and regarding the benefits, risks and duration of suggested treatment with statistically significant difference with the non-educational hospitals with p-value $(<0.001 \&<0.001)$ and $80.8 \%$ received information from attending physician.
Perception of patient about doctor practice of confidentiality and about consent were detected by asking patients some questions as in table (2\&3).

By comparing implementation of patients' rights between different specialists in educational hospitals as introduction before examination showed significant difference with p-value 0.002 , asking permission before starting clinical examination with $\mathrm{p}$-value $<0.001$ and also in asking permission before exposure any part of the body with p-value 0.000 with more in ophthalmology and ENT. While in non-educational hospitals about $100 \%$ of surgeons and obstetricians asked permission before clinical examination and about $33 \%$ of internal medicine doctors and also in asking permission before exposure any part of the body (graph1\&2).

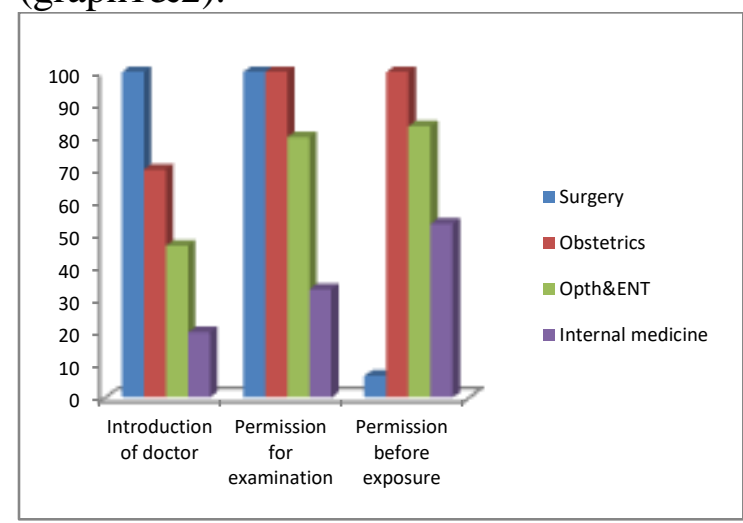

Figure (2): Introduction, permission for clinical examination and permission by different specialties in non-educational hospitals.

About half of patients in surgery department in educational hospital, received information but did not understand it due to use of medical terms and also in information related to benefits, risks and duration of treatment and about $85 \%$ of them received information from attending physician while in obstetric department there were some of withhold truth in oncology cases and this was found in about more than $15 \%$ of cases did not know any information about their clinical 
diagnosis and treatment, in Ophthalmology \& ENT departments about $50 \%$ of patients received information and more than $90 \%$ received it from attending physicians and $41.6 \%$ of patients in internal medicine department received limited information. While in noneducational hospitals, about more than half of patients in obstetric department received information but limited and $40 \%$ did not understand it due to medical terms, $43.3 \%$ of patients in surgery department received limited information while nearly the same percent in ophthalmology \&ENT departments received information about their clinical diagnosis and half of patients in internal medicine received limited information.

The results showed that the healthcare providers in internal medicine department in educational hospitals was not familiar with the informed consent as about $85 \%$ of patients not signed consent while other departments used the consent also, healthcare providers in internal medicine department in non-educational hospitals were not familiar with the informed consent as about $70 \%$ of patients not signed consent while other departments used the consent.

\section{Discussion}

This is a cross-sectional study done in both educational and non-educational hospitals to assess perception of rights among patients in both educational and noneducational hospitals. There was significant difference in perception of rights between patients in educational and non-educational hospitals.

Socio-demographic factors of the patients were influenced the interaction between a physician and the patient and consequently the medical service quality. ${ }^{11}$ In this study most of participants were from rural villages around the city $(63.36 \%)$ and about $50 \%$ were illiterate and this needed the clinicians to be aware and more sensitive to the culture of patient. Knowledge about the patient sociodemographic variables helps the physician to be more able to communicate with the patient and attain the patient trust. While a study done in developing countries to assess patient satisfaction with their rights the studied participants were from urban area $(82 \%)$ and about $48.5 \%$ of them were below high school. ${ }^{12}$

In this study, more than $43 \%$ of the patients in educational hospitals had taken detailed information about nature of illness, benefit, risks, duration of treatment and its alternatives and about $26.5 \%$ did not understand while $41.7 \%$ of patients in non-educational hospitals had taken information but not understand this is explained due to the using of clinicians medical terms in their explanation. This agreed with a study done in hospitalized patient to assess their understanding of their plan of care about $48 \%$ of patients had information about their plan of care in tests or procedures. ${ }^{13}$

The study found that $54.16 \%$ of patients in non-educational hospitals did not satisfied with the time given to them from doctors mostly in the emergency departments as surgery and obstetrics departments regarding respecting patient's confidentiality, privacy and autonomy in accepting or refusing any treatment or procedure, while $55.2 \%$ of patients in educational hospitals satisfied with the time given to them, lack of satisfaction is due to long time spent in emergency, overcrowding, inadequate infrastructure of the hospitals and increase waiting time for attendance. This did not agree with a Brazilian study done to assess the patient satisfaction in an emergency service, found that the patients had a good level of satisfaction (mean of satisfaction $3.69 \pm 0.54$ ) with the care provided by the team of hospitals mainly nurses, this good 
level of satisfaction presented in this study may attributed to the short time spent in the emergency and lower than in the other units. $^{14}$

While in Pakistan, a study done to assess patient satisfaction with doctor patient interaction by Jalil et al., ${ }^{15}$ found that $54.2 \%$ of patients did not satisfy with time of consultation, this was due to doctor not shared more information and shared only information which is understandable for the illiterate patient. In doing so, other important issues related to health education are ignored by the physicians like explaining the medical condition and safety measures for patients before seeing doctor's clinic. Neither the doctors tell what was diagnosed nor do the patients enquire.

Regarding to withholding information about diagnosis to the patients, in this study about 6 cases in obstetric unit, clinicians withhold the diagnosis from the patients with request from their family, regarded this to their young age and terminal cases. This is not agreed with McCabe et al., ${ }^{16}$ who saw that disclosure of diagnosis and truth-telling is an important ethical issue as beneficence and non-maleficence while Punjani, ${ }^{17}$ said that telling the truth needs to be done in a timely and sensitive manner and in certain situation withhold truth telling may enhance patient care and prevent harm. This also agreed with a cross-sectional study done in India to detect if cancer patient need to know his diagnosis, found that about $94 \%$ of patients had a strong need for information about their illness and treatment. ${ }^{18}$

Regarding to patient satisfaction about (understanding informed consent, enough time before signing consent, reading the consent and who asked him to sign it) in this study. Neary half of patients who had been interviewed in educational hospitals said that they had no enough time to read the consent and about $77.27 \%$ did not read the consent, about $51.7 \%$ of them explained this due to the trust to their doctors but in non-educational hospitals most of the patients said that the doctors not ensured that they understood the consent before signing it. Mohamed et al., ${ }^{19}$ measured the patient satisfaction in Alexandria University hospitals found that, only $48.0 \%$ of patients were satisfied with their treating physician while $(67.0 \%)$ were satisfied with the practice of their doctor in obtaining an informed consent and 62.0\% with having privacy during medical consultation.

\section{Conclusion}

The difference between hospitals in implementation of healthcare ethics depend on the how the physicians practiced it with the patient and how he/she trained to respect privacy and confidentiality of patients more than educational or non-educational hospitals.

Recommendations: Improving the patient satisfcation about the quality of care in hospital through measuring the perception of their rights can bring a lot of advantages such as increased quality of health care services, decreased costs, more prompt recovery, decreasing length of stay in hospitals, lower risk of irreversible physical and spiritual damages and increased dignity of patients through informing them about their rights to participate in decision makingis. We recommended many measure for the hospital adminstrators through appling more education to the physicians about respecting the patients rights, secure access to the patient data, more regulators emphasize the importance of keeping the confidentiality of the patients' medical data in the health field.

Limitation of the study: The present survey had some limitations in coaporation of the patients with the researchers. It relied on 
the patients' mood during filling the questionnaire. This limits the generalization of results to other settings.

\section{References}

1. Özdemir MH, Can İÖ, Ergönen AT, Hilal A, Önder M, Meral D. Midwives and nurses awareness of patients' rights. Midwifery. 2009;25(6):756-65.

2. Merakou K, Dalla-Vorgia P, GaranisPapadatos T, Kourea-Kremastinou J. Satisfying patients' rights: a hospital patient survey. Nursing ethics. 2001;8(6):499-509.

3. Millar M. Patient rights and healthcareassociated infection. Journal of Hospital Infection. 2011;79(2):99-102.

4. Elsayed KA, El-Melegy OA, Amaal M. The effect of an educational intervention on nurses' awareness about patients' Rights in Tanta. Journal of American Science. 2013;9(9):210-9

5. Abedi G, Shojaee J, Moosazadeh M, Rostami F, Nadi A, Abedini E, Palenik CJ, Askarian M. Awareness and observance of patient rights from the perspective of Iranian patients: a systematic review and metaanalysis. Iranian journal of medical sciences. 2017;42(3):227.

6. Hall DE, Prochazka AV, Fink AS. Informed consent for clinical treatment. Cmaj. 2012;184(5):533-40.

7. Zeina HA, El Nouman AA, Zayed MA, Hifnawy T, El Shabrawy EM, El Tahlawy E. Patients' rights: a hospital survey in South Egypt. Journal of Empirical Research on Human Research Ethics. 2013;8(3):46-52.

8. Almoajel AM. Hospitalized patients' awareness of their rights in Saudi governmental hospital. Middle-East Journal of Scientific Research. 2012;11(3):329-5.

9. Younis AA, Hassan AH, Dmyatti EM, Elmubarak MA, Alterife RA, Salim RE, Mohamed SA, Ahmed WS. Awareness and practice of patients' rights among hospitalized patients at Wad-Medani Teaching Hospital,
Sudan. EMHJ-Eastern Mediterranean Health Journal. 2017;23(2):80-6.

10. Bazmi S, Kiani M, Hashemi Nazari SS, Kakavand M, Mahmoodzade R. Assessment of patients' awareness of their rights in teaching hospitals in Iran. Medicine, Science and the Law. 2016;56(3):178-83.

11. Mosadeghrad AM. Factors affecting medical service quality. Iranian journal of public health. 2014;43(2):210.

12. Mastaneh Z, Mouseli L. Patients' awareness of their rights: insight from a developing country. International journal of health policy and management. 2013;1(2):143

13. O'Leary KJ, Kulkarni N, Landler MP, Jeon J, Hahn KJ, Englert KM, Williams MV. Hospitalized patients' understanding of their plan of care. InMayo Clinic Proceedings 2010; Vol. 85, No. 1,.47-52.

14. Fátima Levandovski P, Dias da Silva Lima MA, Marques Acosta A. Patient satisfaction with nursing care in an emergency service. Investigación y educación en enfermería. 2015;33(3):473-81.

15. Jalil A, Zakar R, Zakar MZ, Fischer F. Patient satisfaction with doctor-patient interactions: a mixed methods study among diabetes mellitus patients in Pakistan. BMC health services research. $2017 ; 17(1): 155$.

16. McCabe MS, Wood WA, Goldberg RM. When the family requests withholding the diagnosis: who owns the truth? Journal of Oncology Practice. 2010; (2):94.

17. Punjani NS. Truth telling to terminally ill patients: To tell or not to tell. J Clin Res Bioeth. 2013 ;4(159): 2.

18. Laxmi S, Khan JA. Does the cancer patient want to know? Results from a study in an Indian tertiary cancer center. South Asian journal of cancer. 2013;2(2):57.

19. Mohamed AM, Ghanem MA, Kassem AA. Knowledge, perceptions and practices towards medical ethics among physician residents of University of Alexandria hospitals, Egypt. Eastern Mediterranean Health Journal. $2012 ; 18(9)$. 